\title{
Communicating with first year medical students to improve Communication Skills teaching in The University of the West Indies
}

\author{
Stella Williams, Bidyadhar Sa, Paula Nunes, Keith Stevenson \\ Faculty of Medical Sciences, University of the West Indies, Trinidad and Tobago \\ Correspondence: Stella Williams, Faculty of Medical Sciences, University of the West Indies, Trinidad and Tobago. \\ Email: stella.williams@sta.uwi.edu
}

Accepted: March 10, 2010

\begin{abstract}
Objectives: This paper reports first year Caribbean medical students' preferred and least preferred Communication Skills teaching styles. It also reports their views on assessment and what qualities they valued in a good Communication Skills teacher.

Methods: Questionnaires were administered to first year students at the end of Semester One and the data compared with the results of a study using the same questionnaire format in the UK.

Results: Caribbean medical students favoured interactive lectures with opportunities for discussion over the didactic formal lecture. The least preferred modes of teaching selected were private study, formal lecture, role play and student presentations. The qualities that students rated highly in their Communication Skills teachers were being a skilled teacher and being knowledgeable and approachable.
\end{abstract}

The preferred assessment style was a 50-50 balance between coursework and exam.

Conclusions: First year medical students in the Caribbean studying Communication Skills preferred interactive lectures with opportunities for discussion. Their explanations indicated that interactive lectures provided more stimulation allowing opportunities for learning and greater retention of information. Students also found small group discussions with constructive feedback helpful in developing their own communication skills. Other international faculty may find this approach of establishing students' preferences for teaching style useful in planning their curriculum delivery.

Keywords: Teaching styles, student preferences, communication teaching, West Indies medical education

\section{Introduction}

There is increasing evidence of communication skills training strategies having positive influences on: patient recall and understanding, adherence; symptom resolution and physiological outcomes; patient and physician satisfaction demonstrated by a significant reduction in malpractice claims. ${ }^{1-3} \quad$ However, delivering communication skills teaching programmes in medical schools poses a number of challenges.

First there is the general lethargic institutional support. ${ }^{4}$ A second challenge is linked to the growing student numbers making small group delivery difficult to resource. A third is the general resistance of students to communication teaching manifested in high absenteeism rates and depressingly a general belief amongst students that communication

is 'caught not taught' and that communication classes "interfere with medical courses". ${ }^{5}$ Such beliefs are found among students and even consultants who have never experienced formal undergraduate or postgraduate training in communication skills. ${ }^{6,7}$

In the US, Wright et al. ${ }^{8}$ conclude that 'more research is needed to examine how the perceptions of communication skills training influences provider behaviour. Interventions targeting effective learning of communication skills, in conjunction with cognitive and behavioural training, need to be developed to help medical students understand the importance of communication and the complexity of communication issues in health care'.

In the UK Stevenson and Sander ${ }^{9-11}$ developed an inter- 
est in researching student preferences for teaching through work carried out with UK Open University students and then developed the University Students' Expectations of Teaching (USET) questionnaire, which they used with over 350 medical, business studies and psychology students. ${ }^{12-13}$ In the USET study ${ }^{12}$ the researchers found that UK first year students, irrespective of course followed, expected to be taught by formal lecture where a lecturer delivered the information and students took notes. The students however if given a choice would have preferred to be taught by a method where information was provided and then student discussion was involved. The research also showed that with UK medical students it was student presentations and role play that were, along with formal lectures, the least preferred teaching styles.

There is no guarantee that the findings from UK would generalize to preferences of teaching in other cultures where for example formal teaching is still valued or thought to be the most effective method of instruction. For example in the West Indies teaching in secondary schools is still predominantly that of the didactic lecture. Given that nearly all first years medical students taking up their place in The University of West Indies, St Augustine Campus (96\% in this study) would have experienced Caribbean schooling the opportunity to test the generalisability of the USET study findings was possible.

Communication Skills is taught as a two semester course at The University of the West Indies (St Augustine Campus) to all first year medical students. The syllabus covers the theoretical principles of communication as well as locating those principles into the specific context of medical communication. The syllabus is presented mainly through lectures and small group teaching where students are encouraged to discuss and experiment with different types of communication. The course has a continuous assessment component and various forms of assessment are introduced as the course progresses. At the time of this study there was a consensus amongst faculty of medical sciences staff at The University of the West Indies (St Augustine Campus) that students would prefer the formal methods of instruction with which they were familiar. The research team decided to ask the first year medical faculty students what they would prefer with regard to teaching and assessment strategies in the delivery of communication skills courses.

\section{Objectives}

1. To explore which teaching approach and modality of assessment Caribbean first year medical students prefer and least prefer in their Communication Skills courses.

2. To explore the most highly rated qualities of a good Communication Skills teacher as perceived by Caribbean first year medical students.

3. To study the students' reasons for their choices.

\section{Methods}

After seeking agreement from the original authors an adapted version of the UK USET study questionnaire was prepared. Modifications were made to adapt the questionnaires for a cultural and contextual fit to the types of learning and assessment used in Communication Skills teaching in the University of the West Indies. The adapted version consisted of three sections (A, B and C) and a section requesting the student's background information. Section 'A' dealt with issues relating to what students had hoped to be the teaching and learning approaches in Communication Skills and which teaching approach they wanted least. Section B dealt with preferred assessment modalities for Communication Skills. Section C sought to explore desirable qualities of a good Communications Skills teacher as perceived by the first year medical students. At the end of each section students were invited to give reasons for their answers. They were also asked to provide their most and least preferred methods of assessment.

\section{Ethical approval}

Permission was granted from the Dean of Medical Sciences that first year medical students could be approached and asked if they would take part in the study. The questionnaire was distributed with an explanation of its purpose to all medical students attending the final communications session at the end of semester one. The 92 appropriately completed questionnaires formed the basis of the selected sample of students who gave their informed consent to be part of the study.

\section{Sample}

The sample of 92 completed questionnaires comprised 58.6 $\%$ of enrolled first year medical students. Of these respondents 27 were male (29\%) and 65 female (71\%). A total of $82 \%$ of the sample were under 21 with $18 \%$ aged 21 and above. Virtually all (96\%) of the students were schooled in the Caribbean and the majority (77\%) had come to University directly following secondary school (as shown in Table $1)$.

Table 1. Background features of the selected sample of first year medical student $(n=92)$

\begin{tabular}{lcc}
\hline Characteristic & Number $(\mathrm{n})$ & Percent $(\%)$ \\
\hline Gender & & \\
Male & 27 & 29.35 \\
Female & 65 & 70.65 \\
\hline Age & & \\
Under 21 & 75 & 81.52 \\
Over 21 & 17 & 18.48 \\
\hline Schooling & & \\
Caribbean & 88 & 95.65 \\
Other & 4 & 4.35 \\
\hline
\end{tabular}




\section{Data collection}

Data were collected at the end of first semester with the assumption that students would be better prepared to give informed answers having experienced the different types of teaching and learning environments that are presented to first year Communication Skills students. Moreover it was felt that by this time students would have received feedback (marks and grades) from different modules that had employed these different teaching and assessment styles.

\section{Data analysis}

Data were collated and presented in tabular and graphical form. The preferences provided by students were subjected to percentages technique. Responses yielded from openended questions were subjected to thematic analyses with direct quotes provided to illustrate where appropriate.

\section{Results}

\section{Course delivery}

The first item looked at was 'hoped for teaching." Most students ranked interactive lectures as their first preference (64\%); formal lecture was the next hoped for choice (24\%), with negligible numbers choosing any of the other four options: student presentations, group work, private study or student role play (as depicted in Figure 1).

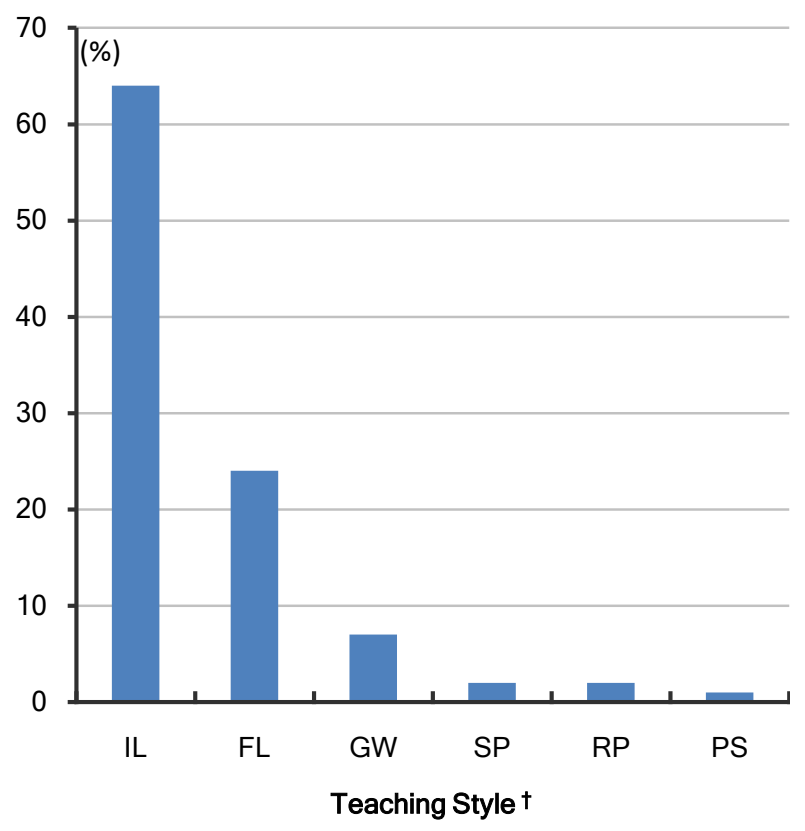

Figure1. Student preference of teaching style $(n=92)$

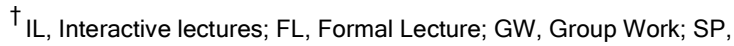
Student Presentation; RP, Role Play; PS, Private Study.

Students' least wanted teaching approach was Private Study chosen by $30.4 \%$ of the sample followed by Formal Lecture (19.6\%), Student Presentations (19.6\%) and Role Play (19.6\%) which were tied as second least wanted approach (as shown in Table 2).
Table 2. Least preferred teaching styles $(n=92)$

\begin{tabular}{lcc}
\hline Teaching Style & Number (n) & Percent (\%) \\
\hline Private Study & 28 & 30.4 \\
Formal lecture & 18 & 19.6 \\
Student Role Play & 18 & 19.6 \\
Student Presentations & 18 & 19.6 \\
Group Work & 9 & 9.8 \\
Interactive Lecture & 1 & 1.1 \\
\hline
\end{tabular}

\section{Assessment}

Students were asked to select their preferred assessment model in Communication Skills. The majority (78\%) of students preferred a final assessment that included a balance between course work and a written exam. When pressed to select the 'percentage balance' $63 \%$ preferred an assessment model where course work counted for at least $50 \%$ of the pass mark. In terms of coursework assessment an online quiz was the most popular choice $(45 \%)$ with the lowest vote $(3 \%)$ going to Film / Cartoon analysis.

\section{Analysis of open ended questions}

When asked to outline the reasons for choosing their preferred teaching and learning method in Communication Skills students indicated that they preferred the interactive lecture because it provided a class environment which is 'comfortable,' 'stimulating,' and 'fun'. The interaction 'assists the learning process and retention, helped 'develop communication skills' and 'stimulated discussion' and also gave 'more perspectives.' Some students indicated that the interactive lecture led to 'greater understanding' helped to 'clarify any ambiguities' and there was 'more feedback'.

\section{Qualities of a good teacher}

Students were asked to rank the most desirable qualities of a good teacher. The qualities most sought were a teacher who had 'good 'teaching skills (32\%) and was knowledgeable (32\%). In second place came "approachable' (24\%). Punctuality and Cooperativeness had the lowest ranks in most desirable qualities of a good teacher (as shown in Table 3).

Table 3. Qualities of a Good Teacher $(n=92)$

\begin{tabular}{lcc}
\hline Qualities & Number $(\mathrm{n})$ & Percent (\%) \\
\hline Teaching Skill & 29 & 31.5 \\
Knowledge & 29 & 31.5 \\
Approachable & 22 & 24 \\
Enthusiasm & 10 & 11 \\
Organization & 2 & 2 \\
Punctuality & 0 & 0 \\
Cooperativeness & 0 & 0 \\
\hline
\end{tabular}




\section{Discussion}

The main aim of this study was to determine first year Caribbean medical school students' preferences for teaching, learning and assessment in the subject area of communication skills. In addition, the study sought to find out what students considered were the important attributes of a Communication Skills teacher in supporting their learning.

The majority of students (82\%) in this study population were around 18-19 years on entry to the Faculty of Medical Sciences and virtually all (96\%) had been schooled in the Caribbean. It was therefore expected that their knowledge of teaching and learning styles would have been limited to their West Indian secondary school experiences. Faculty staff when asked what teaching style the medical students would select suggested that the students would prefer the didactic style they were used to in their school environment. The findings, however, on preferred teaching style mirrored Sander et al's UK study ${ }^{12}$ with Caribbean students overwhelmingly choosing the interactive lecture over 5 other styles presented. The findings presented here may help other faculty who teach Caribbean students to rethink the style of lecture they prepare in future. The popularity of the choice of lecture in its interactive form however, should not hide the fact that the students still anticipate a formal lecture but it seems the students value the opportunity to discuss the content with classmates and lecturer.

The least popular teaching approach in this study was 'Private Study' with $30.4 \%$ of the sample selecting it. The dislike expressed towards private study is a new finding when compared with the UK USET study. The authors suggest that this choice may reflect a particular concern of Caribbean students who may be displaying an anxiety here about being asked to study without guidance. The second least preferred teaching method was equally shared by a combination of the formal lecture, student presentation and role play. The finding of these three methods as least preferred methods corresponds with findings from a secondary analysis of UK USET study. ${ }^{13}$ It will require further research to establish exactly why role play and student presentations are not liked by the Caribbean students.

The form of assessment answers showed clearly the value students put on course work contributing to their overall mark or their concern that everything should not rest on the results of their performance on a final exam. These students overwhelmingly chose an assessment model with course work contributing at least $50 \%$ to the final mark as the one they thought was an appropriate balance for exam and continuous assessment marks.

The top three qualities selected of a good teacher were: having good teaching skills; being knowledgeable; being approachable. The Caribbean approach to timekeeping was evident with not even a single student believing that teacher punctuality was an important teacher quality.

\section{Limitations of the study}

The study reports the findings of 92 medical students which reflected $58 \%$ of the St. Augustine Campus, medical student intake for the academic year 2008/9. The year's entire cohort was therefore not included and a bias may be present in the views expressed. Nevertheless, the sample was more than half of the intake and reflected it in terms of gender, age and previous schooling. The UK USET questionnaire although adapted to the Communications teaching context of The University of the West Indies still relied on each student equally understanding the styles of teaching that they were asked to consider. The findings represent a snapshot of first year student views and they may change over the year and change again in subsequent years as they mature and recognize the value of particular teaching styles that they do not currently understand.

\section{Conclusion}

In summary, Caribbean first year medical students being taught Communication Skills in a Caribbean medical school seem to be saying that interactive lectures are the way forward where information is provided and an opportunity given for discussion. Formal lectures are not generally liked and role play and private study are not activities that students feel are useful. Good lecturers are perceived to be those that have good teaching skills, are knowledgeable about their subject and are approachable.

When asked to outline the reasons for choosing their preferred teaching and learning method students indicated that they preferred the interactive lecture because it provided a more interesting and stimulating class environment. The students were able to identify the value of interactive lectures where the interaction increased the opportunity for learning and retention of information. Furthermore there was a recognition that interactive discussion can provide more perspectives that therefore stimulates deeper thinking. Finally students were also able to identify discussion as an opportunity to develop their own communication skills and receive constructive feedback.

In recent times, most Universities, including the University of the West Indies (St. Augustine Campus) have been moving towards a learner-centred pedagogy. Implicit to this approach is an awareness of students' attitudes to learning curricular content. We hope that this paper will encourage other faculty to work with their students in establishing what the students' preferred and least preferred teaching styles are and what their reasons are. This will provide data that can be discussed by staff with the knowledge that the information is provided by the students they teach and can be the beginning of the involvement of students in the learning process. ${ }^{13}$ 


\section{References}

1. Laidlaw TS, MacLeod H, Kaufman DM, B. Langille DB, Sargeant J. Implementing a communication skills programme in medical school: needs assessment and programme change. Med Educ. 2002;36:115-124.

2. Kurtz SM. Doctor-Patient Communication: Principles and Practices. Can J Neurol Sci. 2002;29:Suppl2 - S23-S29.

3. Stewart MA. Effective physician-patient communication and health outcomes: a review. Can Med Assoc J. 1995;152:1423-33.

4. Novack DH, Volk G, Drossman DA, Lipkin M. Medical interviewing and interpersonal skill teaching in the US medical schools-practice, problems and promise. JAMA. 1996;269:2101-5.

5. Reece I, Walker S. Teaching, training and learning: A practical guide 4th ed. Gateshead: Business Education Publishers; 2000.

6. Watmough S, Garden A, Taylor D. Does a new integrated PBL curriculum with specific communication skills classes produce Pre-Registration House Officers (PRHOs) with improved communication skills? Med Teach. 2006; 28:264269.

7. Barnett M, Fisher J, Cooke H, Dale J. Developing an audit instrument for breaking bad news. Qual Primary Care. 2003;11:287-91.

8. Wright K, Bylund C, Ware J, Parker P, Query J, Baile W. Medical student attitudes toward communication skills training and knowledge of appropriate provider-patient communication skills: A comparison of first-year and fourth-year medical students. 2006 [cited 12 November 2009]; Available from: http://www.med-edonline.org/pdf/Res00171.pdf.

9. Stevenson K, Sander P, Naylor P. Student perceptions of the tutor's role in higher education distance learning. Open Learning. 1996;11:22-30.

10. Stevenson K, Sander P, Naylor P. ELPO: A model that uses student feedback to develop effective open tutoring. Open Learning. 1997;12:54-59.

11. Stevenson K, Sander P. How do Open University students expect to be taught at tutorials? Open Learning. 1998;13:42-46.

12. Sander P, Stevenson K, King M, Coates D. University students' expectations of teaching. Studies in Higher Education. 2000;25:309-323.

13. Stevenson K, Sander P. Medical students are from Marsbusiness and psychology students are from VenusUniversity lecturers are from Pluto? Med Teach. 2002;24:27-31.

14. McIlveen H, Greenan K, Humphreys P. Involving students in teaching and learning: A necessary evil? Quality Assurance in Education.1997;5:231-238. 